\title{
BMJ Open Characterisation of the rural indigent population in Burkina Faso: a screening tool for setting priority healthcare services in sub-Saharan Africa
}

\author{
Samiratou Ouédraogo, ${ }^{1,2}$ Valéry Ridde, ${ }^{1,2}$ Nicole Atchessi, ${ }^{1,2}$ Aurélia Souares, ${ }^{3}$ \\ Jean-Louis Koulidiati, ${ }^{3}$ Quentin Stoeffler, ${ }^{4}$ Maria-Victoria Zunzunegui ${ }^{1,2}$
}

To cite: Ouédraogo $\mathrm{S}$, Ridde V, Atchessi N, et al. Characterisation of the rural indigent population in Burkina Faso: a screening tool for setting priority healthcare services in sub-Saharan Africa. BMJ Open 2017;7:e013405. doi:10.1136/ bmjopen-2016-013405

- Prepublication history and additional material for this paper are available online. To view these files please visit the journal online (http://dx.doi. org/10.1136/bmjopen-2016013405).

Received 11 July 2016 Revised 27 April 2017 Accepted 28 April 2017

CrossMark

${ }^{1}$ University of Montreal Public Health Research Institute, Montreal, Canada

${ }^{2}$ Department of Social and Preventive Medicine, University of Montreal School of Public Health, Montreal, Canada ${ }^{3}$ Institute of Public Health, University of Heidelberg, Heidelberg, Germany

${ }^{4}$ Department of Economics, Istanbul Technical University, Istanbul, Turkey

Correspondence to Dr Samiratou Ouédraogo; samioued@yahoo.fr

\section{ABSTRACT}

Background In Africa, health research on indigent people has focused on how to target them for services, but little research has been conducted to identify the social groups that compose indigence. Our aim was to identify what makes someone indigent beyond being recognised by the community as needing a card for free healthcare. Methods We used data from a survey conducted to evaluate a state-led intervention for performance-based financing of health services in two districts of Burkina Faso. In 2015, we analysed data of 1783 non-indigents and 829 people defined as indigents by their community in 21 villages following community-based targeting processes. Using a classification tree, we built a model to select socioeconomic and health characteristics that were likely to distinguish between non-indigents and indigents. We described the screening performance of the tree using data from specific nodes.

Results Widow(er)s under 45 years of age, unmarried people aged 45 years and over, and married women aged 60 years and over were more likely to be identified as indigents by their community. Simple rules based on age, marital status and gender detected indigents with sensitivity of $75.6 \%$ and specificity of $55 \%$ among those 45 years and over; among those under 45 , sensitivity was $85.5 \%$ and specificity $92.2 \%$. For both tests combined, sensitivity was $78 \%$ and specificity $81 \%$.

Conclusion In moving towards universal health coverage, Burkina Faso should extend free access to priority healthcare services to widow(er)s under 45 , unmarried people aged 45 years and over, and married women aged 60 years and over, and services should be adapted to their health needs.

Ethics considerations The collection, storage and release of data for research purposes were authorised by a government ethics committee in Burkina Faso (Decision No. 2013-7-066). Respondent consent was obtained verbally.

\section{INTRODUCTION}

Universal health coverage (UHC) has been a key objective for the international community since the call made by the United Nations in 2012. However, given resource constraints, countries must determine their
Strengths and limitations of this study

To our knowledge, this is the first published study that identified those who constitute an indigent population in a sub-Saharan African country.

- The results of the study provided local authorities in Burkina Faso with useful information on populations that need urgent healthcare coverage.

- This study was limited to certain rural areas in Burkina Faso; further research is needed to assess whether these results can be generalised.

- Due to lack of data, we could not perform comparative analyses of the characteristics of people with and without missing data in the study.

own priorities, and UHC does not mean governments will be able to provide access to all possible health services. High-priority health services should, however, be available to everyone. ${ }^{1}$ UHC implementation could follow the path of progressive universalism, which involves initially targeting indigents to support them proportionally to their level of disadvantage and offer them high-priority services. ${ }^{2}$ Targeting social benefits in low/middle-income countries has proven challenging. ${ }^{3} 4$ More specifically, identifying indigents is a challenge for healthcare sector reform, particularly in Africa, ${ }^{56}$ where two processes have been regularly investigated: community-based targeting (CBT) and proxy mean testing (PMT) ${ }^{78}$ Unlike PMT, there are few studies on CBT in sub-Saharan Africa. In Burkina Faso, CBT consists of a process by which the worst-off are selected by a gender-balanced village selection committee of community members appointed by the village health committee. To avoid any capture of local elite,${ }^{9-11}$ the selection committees' members cannot be administrative officers, village chiefs or health committee 
members. Village selection committees produce lists of indigents whom they select based on a consensual definition and with no predetermined criteria: 'Someone who is extremely disadvantaged socially and economically, unable to look after him/herself, and devoid of internal or external resources'. The process and the definition were introduced and validated by Ridde $e t$ $a l$. in $2007 .{ }^{12}{ }^{13}$ However, they also showed that user fees exemptions are not enough and that more is needed to ensure indigents benefit from services. ${ }^{14}$ Moreover, no study has identified who are those in a state of indigence. Are elderly adults protected informally by their extended families, or do they lack adequate resources to spend on healthcare in the absence of formal government safety nets and old age pensions? What access do poor women have to healthcare in societies where men have the decisional power in the family? In a patriarchal society, is being a woman a driver towards indigence?

In this study, our aim was to identify what makes someone an indigent beyond being recognised by his or her community as needing a card for free healthcare.

\section{POPULATION AND METHODS \\ Setting}

A state-led intervention combining performance-based financing for healthcare with user fees exemptions for indigents was implemented in 10 districts in Burkina Faso in 2014. It provided increased financing to healthcare structures and staff based on quantity and quality of care provided. Higher fee-for-service rates were offered for some services delivered to indigents. ${ }^{15}$ To identify indigents in each district, a CBT process was implemented in villages concerned by the intervention. In each village, the selection committee was given the entire responsibility and autonomy to select the worst-off within their community. These committees each developed a list of indigents based on their perception of the definition suggested by Ridde et al. ${ }^{12}$ These lists were validated by an external committee. The World Bank financed this state-led programme, paying up to 7.2 times more for some consultations for indigents than for those of non-indigents.

The study was conducted in 21 villages in two rural districts of Burkina Faso with an agricultural economy: Diébougou (127857 inhabitants) in the southwest and Gourcy (208740 inhabitants) in the north. With only four general practitioners and no specialists in both districts, health services use in these areas is very low. In 2014, the average annual number of health visits per inhabitant was 1.03 in Diébougou and 0.73 in Gourcy. ${ }^{16}$ These districts are different in terms of agricultural practices, weather conditions and ethnic composition. They therefore represent a diversity of rural contexts in Burkina Faso. Table 1 presents the villages' total populations in 2011 as well as the numbers of non-indigents and indigents included in this study.
Table 1 Total population in each village and number of non-indigents and indigents

\begin{tabular}{lccc}
\hline Villages & $\begin{array}{l}\text { Total } \\
\text { population } \\
\text { in 2011 }\end{array}$ & $\begin{array}{c}\text { Non- } \\
\text { indigents }\end{array}$ & Indigents \\
\hline District of Gourcy & (north region) & \\
\hline Bassi & 3140 & 272 & 18 \\
\hline Palle & 1602 & 100 & 12 \\
\hline Garou & 627 & 26 & 38 \\
\hline Doure & 1297 & 69 & 36 \\
\hline Kibilo & 2799 & 180 & 19 \\
\hline Leleguere & 765 & 50 & 27 \\
\hline Minima & 1413 & 82 & 24 \\
\hline Zankolga & 546 & 35 & 32 \\
\hline Ranoua & 2190 & 124 & 27 \\
\hline Bouloulou & 2131 & 115 & 32 \\
\hline Rassomde & 1940 & 99 & 16 \\
\hline District of Diébougou (south-west region) & \\
\hline Obro & 641 & 47 & 38 \\
\hline Sorindigui & 534 & 55 & 38 \\
\hline Bonfesso & 633 & 94 & 28 \\
\hline Nabere & 864 & 120 & 35 \\
\hline Tansie & 1412 & 88 & 166 \\
\hline Olbontoune & 312 & 27 & 37 \\
\hline Diagnon & 264 & 9 & 27 \\
\hline Diourao & 556 & 32 & 31 \\
\hline Poyo & 216 & 128 & \\
\hline & 950 & & \\
\hline
\end{tabular}

\section{Study sample}

Data were collected between February and April 2015, dry season months when households are more available for interviews than during the agricultural season.

About 10 villages were randomly selected in each district (table 1); all households that included an indigent identified by the CBT were included. For comparison, we randomly selected $85 \%$ of households without indigence in Diébougou and 45\% in Gourcy. Altogether, 2077 non-indigents and 1009 indigents were identified for the study in the two districts.

Data were collected on tablets by trained investigators using Open Data Kit software. The household questionnaire included modules on household composition, education, assets and other dimensions. In households including at least one indigent, an individual health questionnaire survey was administered to the indigent member(s). In households without an indigent, an individual member was randomly selected and administered the same individual health questionnaire.

\section{Study variables}

Individual-level variables were selected based on health determinants reported in previous studies in Africa ${ }^{17-20}$ : 
- Demographic characteristics: gender (male, female), age (18-24, 25-34, 35-44, 45-59, 60+), marital status (single, monogamous union or living together, polygamous union, divorced or separated, widowed)

- Socioeconomic characteristics: highest level of education (none, primary school, secondary school); engaging in income-producing activity in the past 7 days; difficulties satisfying food needs; financial constraints making it difficult to buy food, use the healthcare centre, or buy medicines

- Health: self-rated health (poor, not poor); self-reported chronic disease; visual impairment

- Physical functioning: physical disability; limitations in walking $400 \mathrm{~m}$; upper limb strength limitations

\section{Ethics}

An ethics committee of the Government of Burkina Faso approved the study (Decision No. 2013-7-066). Respondent consent was obtained verbally.

\section{Statistical methods}

$\chi^{2}$ tests were used to compare socioeconomic characteristics, health status and physical functioning of non-indigents and indigents.

To create classification models (IBM SPSS Statistics V. 22), we used the IBM SPSS Decision Trees procedure. Classification and regression tree analysis is a non-parametric exploratory method that partitions the sample using explanatory variables so that segments obtained are as homogenous as possible with regard to the dependent variable. ${ }^{21}$ Using the Quick Unbiased Efficient Statistical Tree method, we built a model that allowed us to select socioeconomic, health status and physical functioning characteristics that were most likely to split non-indigents from indigents. All variables available for this study were specified in the decision tree model. Fourteen were included in the final model procedure: gender, age, highest level of education, marital status, engaging in income-producing activity, financial difficulties (financial constraints making it difficult to buy food or use the healthcare centre), perceived poor health, chronic disease, visual impairment, disability, ability to walk and physical strength. Variables that did not contribute significantly were automatically removed from the final model.

The target category was 'indigent'. For each split, the association between each covariable and the target category was computed using Pearson's $\chi^{2}$ test. At each step, the covariable showing the highest association with the target category was selected for splitting. ${ }^{21}$ When specifying the model, we set an equal cost of misclassification for non-indigents and indigents, the value of alpha for splitting nodes at 0.05 , minimum parent node size at 50 and parent node size at 25 . We also performed a sensitivity analysis setting a higher cost of misclassification for indigents (twice that for non-indigents). We randomly split the sample into two subsamples (both including non-indigents and indigents), and the models were fitted using the first as a training sample and then testing on the second subsample. Trees were generated to maximum size, where each node contained single-class data or no test offered improvement on the mix of classes at that node, then pruned to avoid overfitting. We also assessed the screening performance of the test tree using CBT as a base-case standard for classification of indigents and non-indigents, since this was the approach adopted by the authorities in Burkina Faso to identify indigents for access to services.

\section{RESULTS}

We identified 2077 non-indigents and 1009 indigents for the study in the two districts. A total of 1783 (85.8\%) non-indigents and $829(82.2 \%)$ indigents aged 18 years and over with complete questionnaires were considered in the present analysis. Indeed, during the period of the interview, 58 indigents were absent from their house, 13 were sick, 22 were too old to respond to the questionnaire, 49 were disabled, 30 did not complete their interview and 8 indigents had died. A total of 294 non-indigents' questionnaires were incomplete and could not be used for the analyses. Unfortunately, we did not have details on the missing questionnaires for the non-indigents.

\section{Characteristics of the study population}

Of the total sample population, $1433(54.9 \%)$ lived in Gourcy, 1555 (59.5\%) were women and $574(22.0 \%)$ were aged 60 years and over. Most were illiterate $(2312,88.5 \%)$; more than one-third $(1004,38.4 \%)$ had difficulties satisfying food needs; $9.4 \%$ (246) had difficulties walking 400 $\mathrm{m}$, and $15.5 \%$ (406) perceived their health as poor.

Table 2 presents the study sample characteristics by indigent status. Indigents were more likely to be women, older, illiterate and/or widowed. They were also more likely to be in poor health and to find it financially difficult to cover basic needs.

\section{Classification of non-indigents and indigents}

Figure 1 presents the test tree diagram. Age, marital status, gender, upper limb strength limitations and financial constraints preventing healthcare centre use and purchase of foodstuffs were the best covariates for separating non-indigents from indigents. All $\mathrm{p}$ values for splitting the nodes were below 0.0001 . We used colour codes to represent tree nodes according to proportions of indigents: red (nodes 3, 9 and 15, with proportions of indigents above $75 \%$ ), orange (nodes $1,5,8,11,18,19$, proportions between $50 \%$ and $75 \%$ ), yellow (proportions between $25 \%$ and $50 \%$ ) and green for groups with proportions under $25 \%$. Red nodes (3, 9 and 15) could be used as screening tests with high specificity. Since the first partitioning variable, aged 45 years and over, was so strongly associated with indigence, we developed separate screening schemes for those aged 45 years and over and those under 45 . 
Table 2 Comparison of socioeconomic characteristics and health status between non-indigents and indigents

\begin{tabular}{|c|c|c|c|c|c|c|}
\hline \multirow[b]{3}{*}{ Variables } & \multirow[b]{3}{*}{ Total number } & \multicolumn{2}{|c|}{ Non-indigents } & \multicolumn{2}{|c|}{ Indigents } & \multirow[b]{3}{*}{$p$ value } \\
\hline & & Number & Percentage & Number & Percentage & \\
\hline & & \multicolumn{2}{|l|}{1783} & \multicolumn{2}{|l|}{829} & \\
\hline \multicolumn{6}{|l|}{ District } & $<0.0001$ \\
\hline Diébougou & 1179 & 631 & 35.4 & 548 & 66.1 & \\
\hline Gourcy & 1433 & 1152 & 64.6 & 281 & 33.9 & \\
\hline \multicolumn{6}{|l|}{ Gender } & $<0.0001$ \\
\hline Male & 1057 & 802 & 45.0 & 255 & 30.8 & \\
\hline Female & 1555 & 981 & 55.0 & 574 & 69.2 & \\
\hline \multicolumn{6}{|l|}{ Age (years) } & $<0.0001$ \\
\hline 18-24 & 368 & 364 & 20.4 & 4 & 0.5 & \\
\hline $25-34$ & 555 & 524 & 29.4 & 31 & 3.7 & \\
\hline $35-44$ & 457 & 328 & 18.4 & 129 & 15.6 & \\
\hline $45-59$ & 658 & 333 & 18.4 & 325 & 39.2 & \\
\hline $60+$ & 574 & 234 & 13.1 & 340 & 41.0 & \\
\hline \multicolumn{6}{|c|}{ Highest level of education achieved } & $<0.0001$ \\
\hline None & 2312 & 1522 & 85.4 & 790 & 95.3 & \\
\hline Primary school & 213 & 188 & 10.5 & 25 & 3.0 & \\
\hline Secondary school & 87 & 73 & 4.1 & 14 & 1.7 & \\
\hline \multicolumn{6}{|l|}{ Marital status } & $<0.0001$ \\
\hline Single & 111 & 68 & 3.8 & 43 & 5.2 & \\
\hline \multicolumn{7}{|l|}{$\begin{array}{l}\text { Monogamous union or } \\
\text { living together }\end{array}$} \\
\hline Polygamous union & 715 & 562 & 31.5 & 153 & 18.5 & \\
\hline Divorced or separated & 25 & 8 & 0.4 & 17 & 2.1 & \\
\hline Widowed & 453 & 110 & 6.2 & 343 & 41.4 & \\
\hline \multicolumn{6}{|c|}{ Engaged in income-producing activity in the past 7 days } & $<0.0001$ \\
\hline No & 2044 & 1344 & 75.4 & 700 & 84.4 & \\
\hline Yes & 568 & 439 & 24.6 & 129 & 15.6 & \\
\hline \multicolumn{6}{|c|}{ Difficulties satisfying food needs } & $<0.0001$ \\
\hline No & 1608 & 1219 & 68.4 & 389 & 46.9 & \\
\hline Yes & 1004 & 564 & 31.6 & 440 & 53.1 & \\
\hline \multicolumn{6}{|c|}{ Financial difficulties that prevent buying foodstuffs } & $<0.0001$ \\
\hline No & 1561 & 1210 & 67.9 & 351 & 42.3 & \\
\hline Yes & 1051 & 573 & 32.1 & 478 & 57.7 & \\
\hline \multicolumn{6}{|c|}{ Financial difficulties that prevent going to the healthcare centre } & $<0.0001$ \\
\hline No & 1553 & 1250 & 70.1 & 303 & 36.6 & \\
\hline Yes & 1059 & 533 & 29.9 & 526 & 63.4 & \\
\hline \multicolumn{6}{|c|}{ Financial difficulties that prevent buying medicines } & $<0.0001$ \\
\hline No & 1610 & 1280 & 71.8 & 330 & 39.8 & \\
\hline Yes & 1002 & 503 & 28.2 & 499 & 60.2 & \\
\hline \multicolumn{4}{|l|}{ Perceived poor health } & & & $<0.0001$ \\
\hline No & 2206 & 1629 & 91.4 & 577 & 69.6 & \\
\hline Yes & 406 & 154 & 8.6 & 252 & 30.4 & \\
\hline \multicolumn{4}{|l|}{ Chronic disease } & & & $<0.0001$ \\
\hline No & 1592 & 1243 & 69.7 & 349 & 42.1 & \\
\hline
\end{tabular}




\begin{tabular}{|c|c|c|c|c|c|c|}
\hline \multirow[b]{3}{*}{ Variables } & \multirow[b]{3}{*}{ Total number } & \multicolumn{2}{|c|}{ Non-indigents } & \multicolumn{2}{|c|}{ Indigents } & \multirow[b]{3}{*}{$\mathrm{p}$ value } \\
\hline & & Number & Percentage & Number & Percentage & \\
\hline & & \multicolumn{2}{|l|}{1783} & \multicolumn{2}{|l|}{829} & \\
\hline Yes & 1020 & 540 & 30.3 & 480 & 57.9 & \\
\hline \multicolumn{6}{|l|}{ Disability } & $<0.0001$ \\
\hline No & 2297 & 1679 & 94.2 & 618 & 74.5 & \\
\hline Yes & 315 & 104 & 5.8 & 211 & 25.5 & \\
\hline \multicolumn{6}{|c|}{ Perceived limitations in ability to walk $400 \mathrm{~m}$} & $<0.0001$ \\
\hline No & 2366 & 1702 & 95.5 & 664 & 80.1 & \\
\hline Yes & 246 & 81 & 4.5 & 165 & 19.9 & \\
\hline \multicolumn{6}{|c|}{ Perceived limitations in upper limb strength } & $<0.0001$ \\
\hline No & 2282 & 1697 & 95.2 & 585 & 70.6 & \\
\hline Yes & 330 & 86 & 4.8 & 244 & 29.4 & \\
\hline \multicolumn{6}{|c|}{ Visual impairment } & 0.4 \\
\hline No & 2560 & 1745 & 97.9 & 815 & 98.3 & \\
\hline Yes & 52 & 38 & 2.1 & 14 & 1.7 & \\
\hline
\end{tabular}

\section{Screening performance of the classification tree}

Among those aged 45 and over, two nodes (3 and 15) had high prevalence of indigence. Node 3, which comprised those 45 years and over who were unmarried, contained 150 of the total 332 indigents (45\%) in that age group. The sensitivity of 'being unmarried' to detect indigence among those 45 years and over was $45 \%(150 / 332)$, and specificity was $83 \%(218 / 264)$. Node 15, married women aged 60 years and over, had a prevalence of indigence of $81.6 \%$ and could be used to screen for indigence among those 45 years and over who were married, with sensitivity of $34 \%(62 / 182)$ and specificity of $94 \%$ (204/218). By combining nodes 3 and 15 , we obtained a test of indigence among those 45 years and over with sensitivity of $64 \%$ and specificity of $77 \%$.

Among those under 45, there was only one red node: node 9 , being widowed. The sensitivity of 'being widowed' for indigence was $66 \%(55 / 83)$, and specificity was $99.2 \%(610 / 615)$. Combining these two screening criteria for those 45 years and over and those under 45 , we obtained sensitivity of $64.3 \%$ and specificity of $92.6 \%$.

Indigence was largely restricted to being old and unmarried. Indeed, the frequency of indigence among young people ( $<45$ years) who were married or living with a partner was only $4.3 \%$ (table 3 ).

Goodness of fit of the classification tree was evaluated by the index value and the gains and index charts. The index value of the model was above $100 \%$, the gains chart was different from the diagonal reference line and the index chart started above $100 \%$. Risk of misclassification was $14.8 \%$. Overall percentage of correct classification was $85.2 \%$. The sensitivity analysis presented in the appendix figure confirmed that age, gender and marital status were strongly correlated with indigence.

\section{DISCUSSION}

Using survey data on individuals in 21 villages of two rural districts in Burkina Faso, we used classification and regression tree methodology to identify the best indicators of indigence, as defined by the community. Results showed that being aged 45 years and over, unmarried and/or a woman were strong indicators of being an indigent, according to the community-based definition. Using simple rules based only on easy-to-obtain indicators of age, marital status and gender, we were able to detect three-quarters of indigents among those aged 45 years and over and six out of seven indigents among those under 45 .

Population ageing has emerged as a major demographic trend even in low-income countries like Burkina Faso, posing challenges to social institutions. ${ }^{22}$ With a population estimated at 17.59 million in 2014 and a poverty headcount ratio of $46.7 \%$, Burkina Faso is one of the poorest countries in the world. Life expectancy has increased in recent years, estimated at 58 years for males and 59 for females in $2013 .^{23}$ To our knowledge, in middle and low-income countries like Burkina Faso, despite increases in the older adult population generating a greater burden of chronic conditions, ${ }^{24}$ social and health policies to adapt to the changing age structure are rare. McEniry and McDermott ${ }^{25}$ describe low-income countries like Burkina Faso as countries where mortality declined rapidly very late in the 20th century. However, in these countries, the health of older cohorts is shaped by survivorship of poor early-life conditions, resulting in 


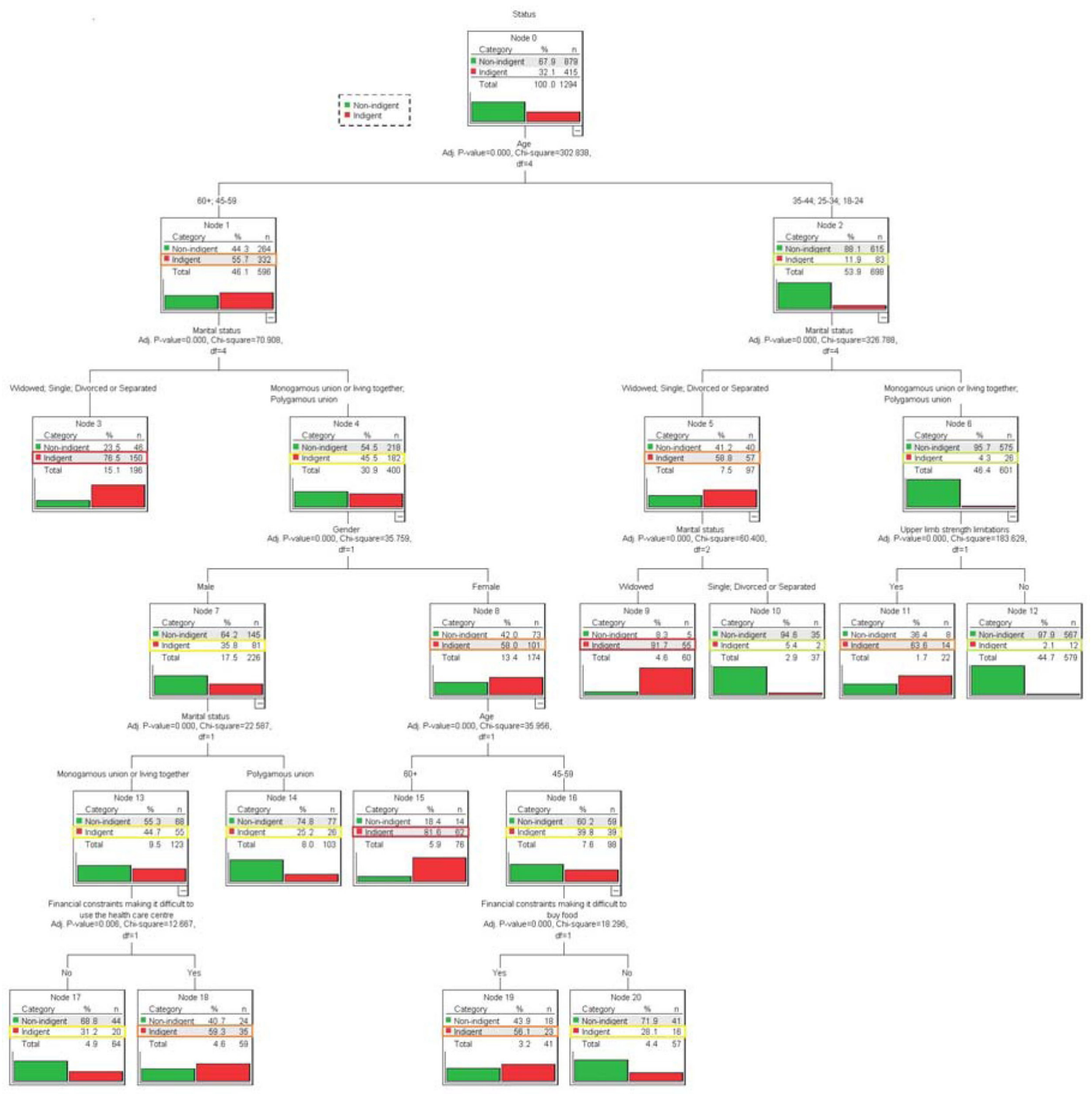

Figure 1 Test tree diagram.

early onset of chronic diseases and high prevalence of frailty. Our study showed that ageing leads to both poor health and deprivation in Burkina Faso. Roth ${ }^{26}$ studying intergenerational relations in Burkina Faso, reported that strength, energy and therefore the opportunity to earn one's keep decreased with age. Those who cannot participate in reciprocal exchanges of gifts or services risk social marginalisation. Yet with no social security ${ }^{197}$ and without exchange relations, there is no social recognition.

Our study also revealed that unmarried people were more likely to be indigents. As marriage in Africa marks the transition to adulthood, single persons are not recognised as adults able to assume responsibilities. ${ }^{26}$ Marriage confers status and dignity, ${ }^{28}$ providing individuals with a sense of meaning and of obligation to others, while inhibiting risky behaviours and encouraging healthy ones. ${ }^{29}$ Previous studies have reported that single, divorced or bereaved persons showed higher mortality and morbidity in specific diseases, ${ }^{30-32}$ as well as lower quality of life ${ }^{33}$ compared with those who were married or cohabiting. The differences between married and unmarried people may reflect a causal effect of marriage and a selection effect: healthier people may be more likely than others to find mates and marry. ${ }^{34}$ 
Table 3 Screening performance of the test tree

\begin{tabular}{|c|c|c|c|c|c|}
\hline Characteristics & Test tree nodes & Sensitivity & Specificity & $\begin{array}{l}\text { Positive predictive } \\
\text { value }\end{array}$ & $\begin{array}{l}\text { Negative predictive } \\
\text { value }\end{array}$ \\
\hline Under 45 & Red node (9) & $0.66(55 / 83)$ & $0.99(610 / 615)$ & $0.92(55 / 60)$ & $0.96(610 / 638)$ \\
\hline All ages & Red nodes $(3,9,15)$ & $0.64(267 / 415)$ & $0.93(814 / 879)$ & $0.80(267 / 332)$ & $0.85(814 / 962)$ \\
\hline
\end{tabular}

Data are percentages, with numbers of non-indigents and/or indigents in parentheses.

Negative predictive value in under 45 was $96 \%$ (red and orange nodes)=((total non-indigents in node 2)-(total non-indigents in nodes 5 and $11)) /($ total indigents in node 2-total indigents in nodes 5 and 11)+(total non-indigents in node 2-total non-indigents in nodes 5 and 11$)) \times 100$.

Sensitivity in under 45 was $66 \%$ (red node)=(total indigents in node 9)/(total indigents in this age group; node 2)x100.

Specificity in all ages was 93\% (red nodes)=((total non-indigents in node 1)-(total non-indigents in nodes 3)]+((total non-indigents in node 2)(total non-indigents in nodes 5))/total non-indigents in all ages groups (nodes 1 and 2)x100.

Positive predictive value in all ages was $80 \%$ (red nodes 3,9 and 15)=(total indigents in red nodes 3,9 and 15)/(total non-indigent and indigents in red nodes 3,9 and 15)x100.

Widows across the globe share two common experiences: loss of social status and reduced economic circumstances. ${ }^{35}$ In developed countries, widowhood is experienced primarily by elderly women, while in low/ middle-income countries it also affects younger women, many of whom are still rearing children. Widowers, even when elderly, are far more likely to remarry. ${ }^{36}$ but this is not the case for widows, who, if they do remarry, rarely do so of their own free will. As a result, many women spend a long period of their lives in widowhood, with all its associated disadvantages and stigmas. ${ }^{35}$ In a recent study, Lloyd-Sherlock et al found that the association between widowhood and being in the poorest household wealth quintile was consistent across most countries (China, Ghana, India, the Russian Federation and South Africa) ${ }^{36}$ In Burkina Faso, the sociocultural context is still marked by beliefs and practices leading to discrimination against women, particularly older women, including widow inheritance, forced marriage and social exclusion of women for witchcraft allegations. Belief in witchcraft is more dominant in rural areas, where poverty usually leads to strained human and in-law relations, and where most illnesses cannot be explained. ${ }^{37}$ Women victims of such violence and discrimination are mostly seniors, have had no children or only girls, have emigrated or their children have not 'succeeded'. They are widowed or postmenopausal, poor and uneducated. ${ }^{38}$ In our study, women who were indigents were likely to carry health consequences of their reproductive history. After surviving adolescent childbirth and multiparity, they were at high risk of lower physical performance, ${ }^{39}$ chronic diseases, incontinence ${ }^{40}$ or fistula. ${ }^{41}$ Supporting this line of evidence, Doulougou $e t a l^{32}$ reported that widows in Burkina Faso were more vulnerable to hypertension than were married women of similar age, education and health behaviours.

The classification tree showed that even married women, if aged 60 years and over, were more likely to be indigents. Power inequalities in gender relationships, affecting access to resources and decision making on sexual and reproductive issues, are frequent in West African societies. ${ }^{42}$ Harmful cultural practices, such as widow cleansing, son preference and others, remain threats to women's health and well-being. ${ }^{43}$ Onadja $e t a t^{44}$ reported that being a woman was positively associated with higher odds of cognitive impairment and mobility disability in Burkina Faso, and the size of associations appeared insensitive to adjustment for various life-course socioeconomic and health conditions. Females make up an increasing proportion of the world's poor. ${ }^{45}$ This situation is exacerbated by age and marital status, as shown in this research.

In this study, we considered CBT as a base-case standard for the classification of indigents and non-indigents. According to Conning and Kenave, ${ }^{46}$ CBT may lead to increased conflict and division within the community and places high time costs on community leaders. Programme goals may be subverted to serve elite interests, or local targeting preferences might differ substantially from national or donor preferences. However, the social acceptability, validity and effectiveness of the CBT process have been documented in Burkina Faso. ${ }^{47}$ Schleicher et $a l,{ }^{9}$ who compared decentralised versus statistical targeting of anti-poverty programmes, found that in the sub-Saharan African context community-based targeting is far more cost-effective than any statistical targeting procedure for welfare programme benefits.

Potential limitations of this study include the fact that the results may not be representative of all of Burkina Faso because the study targeted only certain rural areas. Moreover, self-reported health included in this study may say more about people's health awareness, health expectations and overall life satisfaction than about their actual health, especially in a poor population with little engagement with services.

\section{Policy implications}

The way the state is organised often exacerbates existing social cleavages, intensifying inequalities between rich and poor. For many vulnerable groups, such as older adults, unmarried adults and widowed women, changes over the past decade have eroded important social safety networks and practices. Targeting the poorest for free access to healthcare or financial assistance has emerged as an alternative to UHC in many low and middle-income 
countries. Such targeting requires effective selection strategies. Our results showed that, as identified by the community, the indigent population in some rural areas in Burkina Faso is composed of three groups: widow(er)s under 45 , unmarried people aged 45 years and over, and married women aged 60 years and over. Using the country's 2014 Demographic Health Survey data, we selected and described these groups and found they represented $1 \%$ of the total population under age $45,23 \%$ of those aged 45 and over, and $45 \%$ of people aged 60 and over. Given scarce resources in Burkina Faso, a budget impact analysis is needed to estimate the financial consequences of extending access to free healthcare services to other subgroups of populations. The government's ability and willingness to support and sustain these programmes must be assessed. These analyses should also explore the trade-offs between sensitivity and specificity in the classification of indigents and non-indigents and investigate the consequences of including these groups.

In moving towards UHC, the government of Burkina Faso has implemented, since 2 April 2016, free access to maternal and child healthcare. However, as reported here, there are other vulnerable groups with poor health and limited access to health services. Healthcare in Burkina Faso should include high-priority services to unmarried people under 45 and those aged 45 years and over (as in Senegal, where elderly people have free access to healthcare) ${ }^{49}$ particularly widow(er)s and older women, and services should be adapted to their health needs, including chronic diseases. Extending free access to healthcare services to these vulnerable populations living in rural areas may be a pertinent public health intervention.

\section{Conclusion}

Using an original study method, this research sheds light on indigence by presenting the characteristics of indigents as perceived by their own communities. Indigence is rare among the married population under 45 and frequent among unmarried adults and older adults, particularly widows(er)s and older women. Indigent people reported poorer health, chronic disease and limitations in physical functioning. This implies that free priority healthcare services for indigent people must take into account age and gender, as well as the management of chronic conditions.

Acknowledgements The authors thank Anne-Marie Turcotte-Tremblay for assistance in the editing of the manuscript; thank Yamba Kafando, Jake Robin, Haidara Ousmane Diadie and Philippe Compaore for their assistance during the study; thank the research NGO 'AGIR' and its staff for conducting the interviews; thank 'SERSAP' for coordinating the selection of indigents by the communities; thank the Demographic and Health Surveys (DHS) Programme for providing Burkina Faso's 2014 DHS data.

Contributors S0 performed the statistical analysis, interpreted the results, reviewed the literature and prepared the manuscript. VR was involved in conception of the study design, data collection, statistical analysis, interpretation of results, literature review and manuscript preparation. NA, AS, J-LK and QS participated in conception of the study design, data collection and manuscript preparation. M-VZ was involved in conception of the study design, statistical analysis, interpretation of results, literature review and manuscript preparation. All authors read and approved the final manuscript.

Funding The 'African Region Multi-Donor Trust Fund on Poverty and Social Impact Analysis (PSIA)' funded data collection for this study. The World Bank and the Canadian Institutes of Health Research (CIHR), through the project 'Community research studies and interventions for health equity in Burkina Faso' (Grant number ROH-115213), funded statistical analysis, interpretation and manuscript preparation. VR holds a ClHR-funded Research Chair in Applied Public Health (CPP 137901). The University of Montreal Public Health Research Institute supported the costs related to editing of the present manuscript. The funding bodies did not play any role in the study design, analysis, interpretation of data, writing of the manuscript or decision to submit it for publication.

Competing interests None declared.

Patient consent Not applicable. For this study, the respondent consent was obtained verbally.

Provenance and peer review Not commissioned; externally peer reviewed.

Data sharing statement The entire data set used for this article is available for researchers. For access, please contact the principal investigator Professor Valéry Ridde at this email address: valery.ridde@umontreal.ca.

Open Access This is an Open Access article distributed in accordance with the Creative Commons Attribution Non Commercial (CC BY-NC 4.0) license, which permits others to distribute, remix, adapt, build upon this work non-commercially, and license their derivative works on different terms, provided the original work is properly cited and the use is non-commercial. See: http://creativecommons.org/ licenses/by-nc/4.0/

(C) Article author(s) (or their employer(s) unless otherwise stated in the text of the article) 2017. All rights reserved. No commercial use is permitted unless otherwise expressly granted.

\section{REFERENCES}

1. Voorhoeve A, Ottersen T, Norheim OF. Making fair choices on the path to universal health coverage: a précis. Health Econ Policy Law 2016;11:71-7.

2. Nicholson D, Yates $\mathrm{R}$, Warburton $\mathrm{W}$, et al. Delivering universal health coverage: a guide for policymakers. Report of the WISH Universal Health Coverage Forum 2015. WISH Partners 2015. https://www. imperial.ac.uk/media/imperial-college/institute-of-global-healthinnovation/public/Universal-health-coverage.pdf (cited 2016 May 20).

3. Ellis F. 'We Are All Poor Here': Economic Difference, Social Divisiveness and Targeting Cash Transfers in Sub-Saharan Africa. $J$ Dev Stud 2012;48:201-14.

4. Stoeffler Q, Mills B, del Ninno C. Reaching the Poor: cash transfer program targeting in Cameroon. World Dev 2016;83:244-63.

5. Ridde V. "The problem of the worst-off is dealt with after all other issues": the equity and health policy implementation gap in Burkina Faso. Soc Sci Med 2008;66:1368-78.

6. Atchessi N, Ridde V, Zunzunégui MV. Is the process for selecting indigents to receive free care in Burkina Faso equitable? BMC Public Health 2014;14:1158.

7. Conning J, Kevane M. Community-Based targeting mechanisms for Social Safety Nets: a critical review. World Dev 2002;30:375-94.

8. Hanson K, Worrall E, Wiseman V. Targeting services towards the poor: a review of targeting mechanisms and their effectiveness. In: Bennett S, Gilson L, Mills A, eds. Health, economic development and household poverty: from understanding to action. London: Routledge, 2007:134-54.

9. Schleicher M, Souares A, Pacere AN, et al. Decentralized versus statistical targeting of anti-poverty programs: evidence from Burkina Faso. 2016: p 59. http://archiv.ub.uni-heidelberg.de/volltextserver/ 22223/ (cited 201730 March).

10. Ridde V, Haddad S, Nikiema B, et al. Low coverage but few inclusion errors in Burkina Faso: a community-based targeting approach to exempt the indigent from user fees. BMC Public Health 2010;10:631.

11. Kadio K, Ridde V, Samb OM. Wealth, poverty and local perceptions of poverty in Burkina Faso. 2012. http://fr.slideshare.net/valery_ridde/ wealth-poverty-and-local-perceptions-of-poverty-in-burkina-faso (cited 201730 March).

12. Ridde $\mathrm{V}$, Yaogo $\mathrm{M}$, Kafando $\mathrm{Y}$, et al. A community-based targeting approach to exempt the worst-off from user fees in Burkina Faso. $J$ Epidemiol Community Health 2010;64:10-15.

13. Simporé L, Ridde V, Queuille L, et al; Évaluation de l'efficacité du ciblage communautaire des indigents bénéficiaires de la gratuité des 
soins dans les districts sanitaires de Dori et de Sebba au Burkina Faso. In: Fournier P, Haddad S, Ridde V, eds. Santé Maternelle et accès aux soins en Afrique de l'Ouest. Contributions de jeunes chercheurs. Paris: Harmattan, 2013:209-30.

14. Atchessi N, Ridde V, Zunzunegui MV. User fees exemptions alone are not enough to increase indigent use of healthcare services. Health Policy Plan 2016;31:674-81.

15. Ridde V, Turcotte-Tremblay AM, Souares A, et al. Protocol for the process evaluation of interventions combining performancebased financing with health equity in Burkina Faso. Implement Sci 2014;9:149

16. Ministère de la santé Du Burkina Faso. Annuaire statistique 2014 Ouagadougou: Direction générale des études et des statistiques sectorielles, 2015.

17. Onadja Y, Bignami S, Rossier C, et al. The components of self-rated health among adults in Ouagadougou, Burkina Faso. Popul Health Metr 2013;11:15.

18. Badini-Kinda F. et a/The gap between ideas and practices: elderly social insecurity in rural Burkina Faso / L'écart entre idées et pratiques: l'insécurité sociale des personnes âgées en milieu rural burkinabé. In: de Jong W, Roth C, Badini-Kinda F, Bhagyanath S, ; eds. Ageing in insecurity: case studies on social security and gender in India and Burkina Faso / Vieillir dans l'insécurité: sécurité sociale et genre en Inde et au Burkina Faso: études de cas. Piscataway, NJ: Transaction Publishers, 2005:139-66.

19. Walker JA. Early marriage in Africa--trends, harmful effects and interventions. Afr J Reprod Health 2012;16:231-40.

20. Valmy L, Gontier B, Parriault MC, et al. Prevalence and predictive factors for renouncing medical care in poor populations of Cayenne, French Guiana. BMC Health Serv Res 2016;16:34.

21. Rokach L, Maimon O. Top-down induction of decision trees classifiers - a survey. IEEE Trans Syst Man Cybern 2002;1:12.

22. Kinsella K, He W. An aging world: 2008. International population reports. Washington, DC: U.S. Government Printing Office, 2009

23. The World Bank. Burkina Faso. 2016. http://data.worldbank.org/ country/burkina-faso (cited 201603 March).

24. Oizumi K, Kajiwara H, Aratame N. Facing up to the problem of population aging in developing countries: new perspectives for assistance and cooperation. Tokyo: Institute for International Cooperation, Japan International Cooperation Agency (JICA), 2006.

25. McEniry M, McDermott J. Early-Life conditions, rapid demographic changes, and older adult healthHealth in the developing world. Biodemography Soc Biol 2015;61:147-66.

26. Roth C. Les relations intergénérationnelles sous pression au Burkina Faso. Autrepart: Vieillir au Sud, 2010:95-110.

27. Roth C. et a/Threatening dependency: limits of social security. Old age and gender in urban Burkina Faso / Dépendance menaçante: limites de la sécurité sociale, vieil âge et genre en milieu urbain burkinabé. In: de Jong W, Roth C, Badini-Kinda F, Bhagyanath S, ; eds. Ageing in insecurity: case studies on social security and gender in India and Burkina Faso / Vieillir dans l'insécurité: sécurité sociale et genre en Inde et au Burkina Faso: études de cas. Piscataway, NJ: Transaction Publishers, 2005:107-37.

28. Kyalo P. A reflection on the African traditional values of marriage and sexuality. IJARPED 2012;1:211-9.

29. Waite L, Gallagher M. The case for marriage: why married people are happier, healthier and better off financially. New York: Broadway Books, 2000

30. Joung IM, van de Mheen H, Stronks K, et al. Differences in selfreported morbidity by marital status and by living arrangement. Int $J$ Epidemiol 1994;23:91-7.
31. Hu YR, Goldman N. Mortality differentials by marital status: an international comparison. Demography 1990;27:233-50.

32. Doulougou B, Kouanda S, Rossier C, et al. Differences in hypertension between informal and formal areas of Ouagadougou, a sub-Saharan african city. BMC Public Health 2014;14:893.

33. Han KT, Park EC, Kim JH, et al. Is marital status associated with quality of life? Health Qual Life Outcomes 2014;12:109.

34. Bramlett MD, Mosher WD. Cohabitation, marriage, divorce, and remarriage in the United States. Vital Health Stat 2002;22:1-93.

35. United Nations. Widowhood: invisible women, secluded or excluded. New York: United Nations Division for the Advancement of Women, 2001. Available from. http://www.un.org/womenwatch/daw/public/ wom_Dec\%2001\%20single\%20pg.pdf. (accessed 2016 May 20).

36. Lloyd-Sherlock P, Corso B, Minicuci N. Widowhood, Socio-Economic Status, Health and Wellbeing in Low and Middle-Income Countries. $J$ Dev Stud 2015;51:1374-88.

37. Meel BL. Witchcraft in Transkei Region of South African: case report. Afr Health Sci 2009;9:61-4.

38. Nebie-Zoma DS. L'exclusion sociale pour allégation de sorcellerie, une violence faites aux femmes. 2014. http://www.genreenaction. net/L-exclusion-sociale-pour-allegation-de.html (cited 2016 May 20).

39. Câmara SM, Pirkle C, Moreira MA, et al. Early maternal age and multiparity are associated to poor physical performance in middleaged women from Northeast Brazil: a cross-sectional community based study. BMC Womens Health 2015;15:56.

40. Kepenekci I, Keskinkilic B, Akinsu F, et al. Prevalence of pelvic floo disorders in the female population and the impact of age, mode of delivery, and parity. Dis Colon Rectum 2011;54:85-94.

41. Maheu-Giroux M, Filippi V, Maulet N, et al. Risk factors for vaginal fistula symptoms in Sub-Saharan Africa: a pooled analysis of national household survey data. BMC Pregnancy Childbirth 2016;16:82.

42. Sen G, Östlin P, George A. Unequal, unfair, ineffective and inefficient gender inequity in health: why it exists and how we can change it. final report to the WHO Commission on Social Determinants of Health, September 2007. Geneva: World Health Organization, Women and Gender Equity Knowledge Network, 2007.

43. Durojaye E. 'Woman, But Not Human': Widowhood Practices and Human Rights Violations in Nigeria. Int $J$ Law Policy Family 2013;27:176-96.

44. Onadja Y, Atchessi N, Soura BA, et al. Gender differences in cognitive impairment and mobility disability in old age: a crosssectional study in Ouagadougou, Burkina Faso. Arch Gerontol Geriatr 2013;57:311-8

45. Moghadam MV. The 'feminization of poverty' and women's human rights. Paris: UNESCO, Division of Human Rights, Gender Equality and Development Section, 2005.

46. Conning J, Kevane M. Community-based targeting mechanisms for social safety nets. Social Protection Discussion Paper No. 102. Washington, DC: World Bank, 2001.

47. Savadogo G, Souarès $A$, Sié $A$, et al. Using a community-based definition of poverty for targeting poor households for premium subsidies in the context of a community health insurance in Burkina Faso. BMC Public Health 2015;15:84.

48. Souares A, Savadogo G, Dong H, et al. Using community wealth ranking to identify the poor for subsidies: a case study of community-based health insurance in Nouna, Burkina Faso. Health Soc Care Community 2010;18:363-8.

49. Mbacké Leye MM, Diongue M, Faye A, et al. Analyse du fonctionnement du plan de prise en charge gratuite des soins chez les personnes âgées "Plan Sésame " au Sénégal. Santé Publique 2013;25:101-6. 